\title{
UNA TRILOGÍA DEL PAISAJE NOVECENTISTA ESPAÑOL EN LA OBRA DEL PINTOR FÉLIX LACÁRCEL
}

\author{
por Gerardo Pérez Calero
}

En el presente artículo se aborda el tema del Paisaje de comienzos de siglo a través de la obra de Félix Lacárcel Aparici, valenciano, discípulo de Joaquín Sorolla en su ciudad natal y pintor independiente en Madrid para posteriormente establecerse en Sevilla en 1914, momento de auge del ambiente regionalista en la capital andaluza que asimila el valenciano con toda propiedad, pasando a constituir uno de los más caracterizados pintores de la generación que hace posible una cierta renovación estética al calor del ejemplo, entre otros y sobre todo, de G. Bacarisas.

En este trabajo se analiza la triple versión del paisaje español del momento visto a través de tres de las regiones hispanas más características: Levante, Castilla y Andalucía, haciéndose patente en el mismo los avances técnicos impuestos a comienzos de siglo pero sin olvidar al propio tiempo la tradición secular del género entre los pintores españoles.

The present article looks at the subject of landscape painting at the beginning of the 20th century through the work of the Valencian Félix Lacárcel Aparici, a disciple of Joaquín Sorolla in his hometown and then independent artist in Madrid before settling in Seville in 1914, a time when the regionalist approach was thriving in the Andalusian capital. The Valencian artist assimilated this atmosphere with great naturalness, going on to become one of the most significant painters of a generation which made a certain aesthetic renovation possible, following the example and inspiration in particular of $\mathbf{G}$. Bacarisas.

This study analyses the triple version of Spanish landscape-painting of the time, as seen through three of the most charasteristic regions of Spain: Levante, Castille and Andalusia. In it the technical advances imposed at the beginning of the century are clear, but at the same time the age-old tradition of the genre among Spanish painters is not forgotten.

Los estudios sobre el Arte español del siglo XIX y primer tercio del actual están, por su interés, de plena actualidad desde un tiempo a esta parte. Esta realidad, palpable si se ojea la más reciente bibliografía artística, se hace aún más evidente por lo que se refiere a los estudios sobre la Pintura de las diferentes regiones españolas a las que se aborda con su característica personalidad pese a que todas ellas tienen mucho en común.

El presente trabajo forma parte de un estudio completo sobre el protagonista del mismo ${ }^{1}$ y trata la faceta más interesante de tan desconocido artista, injustamente olvidado, que supo aunar, por su condición de valenciano afincado después en Sevilla tras su paso por Castilla, la esencia de lo levantinomediterráneo, castellano y andaluz con un estilo sutil y atractivo, netamente

1. Tengo en vías de publicación un libro monográfico que bajo el título: "El pintor Félix Lacárcel Aparici (18831975). Un sorollista en Sevilla", recoge en su conjunto la vida y la obra del artista. 
personal, pero cuyas referencias, como se verá, vienen dadas por el ambiente en que vivió, como expresión del rico y variado Regionalismo español emanado de las teorías regeneracionistas del 98 que ven en el Paisaje el medio de descubrir la realidad territorial del país con una doble visión, natural y antropológica ${ }^{2}$.

Pero, cabe preguntarse de inmediato por las bases estéticas del paisaje de nuestro artista, las que hay que buscar no sólo en los modos pictóricos hispánicos -con ser estos muy importantes- propios del último tercio del XIX apoyados en el realismo luminista levantino-andaluz, sino también en la particular visión de algunos simbolistas del color, caso del propio Van Gogh, e incluso en los fauves galos. No en valde, como he sostenido en otras ocasiones, el pintor se mantiene en un particular eclecticismo entre la tradición y la renovación pictórica ${ }^{3}$.

Félix Lacárcel Aparici, nacido en Valencia el 14 de noviembre de 1883, veinte años después que Sorolla, ingresa a los doce de edad en la Escuela de Bellas Artes de la capital del Turia en donde vive el ambiente propiciado por la Academia de San Carlos, de la cual dependía, que no es otro que el de la exaltación de lo autóctono mediante las enseñanzas sobre todo del paisaje y de las escenas costumbristas, siempre bajo el sello propio del ambiente regionalista alegre y luminoso, lo que el joven Félix asimila pronto ejecutando sabrosos lienzos plenearistas inspirados en el entorno natural levantino-mediterráneo.

Esta primera etapa que en rigor se extiende entre 1902 y 1914, si bien posteriormente realiza algún paisaje oriental español, se caracteriza por la espontaneidad de un joven lleno de ilusión al que no faltan quilates artísticos y al que guía un maestro genial: Joaquín Sorolla. El resultado de todo ello se traduce en un tipo de cuadro bien ejecutado, lleno de expresión y que rezuma frescura y amor por su tierra. Poco a poco, llevado por su propia evolución estética, el aprendiz se va convirtiendo en maestro y sus paisajes adquiriendo calidades cada vez más valiosas, pues en aras de esta evolución, aunque siempre dominando el dibujo y la composición como base de su formación artística, el luminismo se va afianzando más y más en su obra, sugestionado por fórmulas sorollescas según las cuales arrancando del "aire libre" pretende hacer realismo llegando al convencimiento de que ningún color existe realmente en la naturaleza, que todos ellos lo son en función de la luz y que la propia forma sufre infinitas variaciones que dependen, en rigor, de la relación color-luz, por un lado, y de la calidad y densidad del aire por otro. En este sentido, Lacárcel, siguiendo en un principio el ejemplo de los impresionistas, gusta de repetir con pequeñas variaciones los temas en diferentes circunstancias ambientales de cuya experiencia obtiene multitud de efectos expresivos y emotivos.

2. Aprovecho la ocasión para agradecer, una vez más, a D. Pilar Lacárcel Gallardo las facilidades dadas para la realización del presente trabajo, al tiempo que lo dedico a la memoria de su hermano D. Ricardo.

3. Véase, entre otros, mi trabajo: "Gonzalo Bilbao y la Pintura del Regionalismo en Sevilla (1880-1930)" en el catálogo de la exposición "Gonzalo Bilbao y la Pintura sevillana de su tiempo". Sevilla, 1988. Pág. 11. 
Por otro lado, desde un principio sus paisajes gustan captar el "alma" del entorno ofreciendo una imágen que no pretende abarcar en el más común de los casos lo gigantesco, sino lo que por mesurado posee límites abarcables, prevaleciendo en él una cierta sobriedad e incluso, a veces, austeridad, genuinamente hispánicas.

Dentro del grupo que estudiamos conviene distinguir entre paisajes costeros y de tierra adentro, diferenciando, al propio tiempo ejemplares valencianos, alicantinos y mallorquines.

Entre 19021903 realiza varios cuadros de marina: Barcas varadas en playa valenciana (tabla, $18 \times 27$. Prop. part.); Puerto de Valencia (L. 37 x 42. Prop. part.); Barcas (dos ejemplares con el mismo título, de 37 x 42 y 35 x 23 respectivamente, ambos óleos sobre lienzo y de propiedad particular) y Paisaje de Sagunto (dos ejemplares con el mismo título, ambos óleos sobre cartón y de propiedad privada, de 22 × 23 y 18 × 28 respectivamente). En todos ellos, pese a lo que podría suponerse, el protagonista no es el puerto como entidad física que aparece al fondo a veces con sus enormes y humeantes barcos, sino las sencillas barcas de pescadores colocadas en primer plano de las que destacan sus leñosos cascos que se hacen multicolores o sus mástiles desnudos o enarbolando, según los casos, blancos velámenes. Son, pese a todo, magníficos estudios de ejecución espontánea y rápida en la captación de las secuencias móviles y en los que dominan los efectos de la luz sobre el agua que adquiere distintas tonalidades combinando con la grisácea bruma del fondo.

Existe una clara afinidad entre esta serie portuaria y otra del mismo tema de Sorolla pintada por estos mismos años, lo que evidencia la senda que sigue Lacárcel buscando un tipo de pintura de grandes efectos visuales, técnica suelta y paleta clara que no es más que la toma de conciencia acerca del hábitat de su país, de su atmósfera, de su luz... Pero, al propio tiempo, estos cuadros, además de su valor puramente estético poseen niveles sencillos de lectura, capaz de integrarse, como dice Muñoz Ibáñez, en una región que reiniciaba una búsqueda de su identidad ${ }^{4}$.

Una variante del tema de marina lo constituye el que representa la $\mathrm{Al}-$ bufera valenciana. En el mismo, el pintor pone cierto lirismo al interpretar sus propios sentimientos ante tan atractivo tema cargado de cierta melancolía, al tiempo que tratado con consumada técnica a base de rápidas y sueltas pinceladas. Un ejemplar, firmado en 1902 (23 x 35. O/l. Prop. part.) representa en la parte izquierda dos típicas barcas albufereñas cuyas siluetas quedan reflejadas en el agua mientras en el extremo contrario aparecen varias de ellas varadas. El cuadro recoge, como si de una ilustración

4. MUÑoZ IBÁÑEZ, M.: La Pintura contemporánea del País Valenciano (1900-1980). Valencia, 1981. 
se tratase, todo el espíritu que inspira también por entonces al escritor y paisano Blasco Ibáñez, intérprete en su novela Cañas y Barro, precisamente publicada este mismo año, de tan sugestivo ambiente, nudamente descrito por ambos y de fuerte trasfondo sentimental.

Los temas de interiores valencianos nos trasladan estética y emotivamente al ambiente hortelano en donde predomina la fecundidad de la tierra levantina. En ellos, tanto si se trata de un paisaje amplio como de pequeñas vistas, destaca la descripción formal de entidades individuales y concretas, su color por su posición relativa. Menciones y descripciones se hacen en general siguiendo el orden de una mirada que parece "pasearse" como si se recrease en la contemplación de las gradaciones cromáticas y lumínicas. Al propio tiempo, mientras en unos el pintor toma como motivo tan sólo unos simples ramajes silvestres algo descarnados, en otros representa a un grupo de árboles del bosque tapizado de hojas secas. En algún caso, el motivo de la representación son rústicos pilares y poyetes blanqueados de alguna alquería con lo que pretende dar simplemente unas sugerencias inmediatas de elementos sencillos pero al propio tiempo llenos de vida, con la intención, además, de crear unos determinados efectos de luces y sombras con fondo claro y diáfano. Sirvan de ejemplo de este grupo cuadros con títulos tan sugerentes como: Calvario de Serra (1902. 18 x 36. L. Prop. part.); Interior de Serra (1903. 35 x 46. L. Prop. part.); Alqueria valenciana (1904. 43 x 67. L. Prop. part.); Arboles en el bosque (1906. 37 x 57. L. Prop. part.); Paisaje valenciano (1908. 30 x 100. L. Prop. part.); Paisaje con barracas (1909. 9 x 14. O/Cartulina. Prop. part.); Apunte de Serra (del que se conocen varios ejemplares de 1916, 1917 y 1918, de 11 x 21 , $18 \times 23$ y $19 \times 23$ respectivamente, todos ellos sobre lienzo o cartón y pertenecientes a colecciones particulares); Pequeña huerta valenciana (1917. $18 \times 23$. Oleo sobre cartón. Prop. part.); Paisaje de un barranco de Vétera (s/d. $54 \mathrm{x}$ 94. Prop. part.). En otras ocasiones los interiores valencianos, especialmente los de Serra, recobran vida al ofrecernos, como si de un escenario teatral se tratase, una representación al fondo consistente en el conjunto del caserío del que destacan las torres de las iglesias o de algún castillo, cual si fuesen personajes erguidos en medio del follaje.

En todos ellos, junto a valores puramente descriptivos, el pintor busca alguna motivación social o laboral. Sirva de ejemplo antológico la representación que bajo el título De labrar ejecuta en 1906, actualmente en paradero desconocido. Fue galardonado en la Exposición Nacional de ese año y pertenece por antonomasia al estilo de obras de "tesis" que tan en boga se puso en España tras la Generación del 98, tanto en Literatura como en Artes plásticas, contándose entre los cultivadores de estas últimas a Sorolla y Gonzalo Bilbao. El cuadro de Lacárcel ejemplariza la condición social del jornalero agrícola que tan bien ilustrara Machado en sus versos: 
“...Campos ubérrimos.

La tierra da lo suyo; el sol trabaja

El hombre es para el suelo:

Genera, siembra y labra

y su fatiga unce la tierra al suelo".

Mallorca atrae también la atención del pintor en esta su primera etapa paisajística interesado por la luz y el color que le animan a representar los hermosos rincones isleños pletóricos de claridad y tonalidades cromáticas, en una época, además, en que las condiciones de la vida balear eran idilicas por su aislamiento y sus condiciones particulares de existencia.

También en esta ocasión se nos ofrecen dos variantes del paisaje isleño: el costero y el de tierra adentro.

El primero muestra bellísimas y abruptas calas con sus desnudas y cortantes laderas que dan sombra a las recoletas y apacibles playas situadas a sus pies. Invariablemente el pintor coloca en el cuadro la nota humana que revitaliza al paisaje, ora la minúscula barquilla del sencillo pescador que pone la blanca tonalidad entre tanto verde, amarillo y azul: Paisaje de Torrent de Paret ${ }^{5}$; ora, un faro en permanente vigilia que parece otear orgulloso el limpio horizonte mediterráneo: Faro de Mallorca, obra de 1912, de 17 x 23. Oleo sobre cartón . entelado y de propiedad particular.

Los interiores baleáricos nos ofrecen, en cambio, lo adusto del suelo isleño: viejos troncos secos de olivo rojos o cenicientos que se retuercen cual si de rocallas se tratasen expuestos a la implacable fogosidad de la canícula mediterránea. Por su técnica son magistrales, compuestos a base de manchas de color con importante juego de luces y sombras proyectadas éstas por la propia arboleda sobre el suelo o entre los recónditos huecos que, a modo de profundas cuevas, dejan los árboles en sus entrañas 6 .

Por lo excepcional de su fecha hay que mencionar dentro de este grupo del paisaje levantino-mediterráneo un ejemplar tardío ejecutado en 1952 que representa el Castillo de Santa Catalina de Alicante (30 x 45. O/t. Prop. part.).

Castilla es el segundo punto de atracción, en orden cronológico, para pintor tan ávido de captar la rica variedad paisajística hispana.

Pese a que podría presumirse un cambio en el interés del pintor por mostrarnos ahora las otonales tonalidades de las viejas y pardas tierras castellanas, sin embargo, el valenciano no puede por menos que buscar también en el centro peninsular los efectos preciosos de su luz en los pintorescos y románticos jarḍines o sobre los altos y silenciosos pinares, tan bien cantados por Azorín y que

5. De él se conocen varias versiones con diferentes medidas, todos oleos sobre lienzo, de propiedad privada.

6. Existen varios cuadros alusivos al tema fechados en 1912, en óleos sobre lienzo o cartón y en diferentes colecciones privadas. 
desafiantes se elevan al cielo, como ve el artista en las cercanías de Madrid. Son paisajes ideales, en donde la luz, ¡Siempre la luz para un valenciano!, está finamente aprisionada en la vibración cálida de sus colores, paisajes, en fin, cargados de lirismo, sonoros que, como los posteriores andaluces, están también preñados de humanidad y ternura.

Aranjuez constituye por sus Reales Sitios lugar privilegiado para explayar toda suerte de sutilezas coloristas matizadas por su particular luz que tan bien captase el catalán Rusiñol (+1931) por lo que hace a la elegancia en su interpretación por su peculiar huella modernista de talante franco. En esta línea, también Lacárcel al manifestar su admiración por el paisajista catalán, hace lo propio con sus ejemplares aranjuecinos llenándolos de tono moderno y armonioso señorío. Sirva de ejemplo de todos ellos un ejemplar de 1907 (52 x 91. O/l. Prop. part.) que representa un bello estanque con templete clasicista y frondosa vegetación que queda reflejada en el agua, intepretando con sutileza magistral el análisis de la luz a través de los colores al modo impresionista.

Otro motivo especialmente querido por el pintor en su particular versión de Castilla, lo constituye la arboleda y el pinar. En ellos pone su alma al expresar líricamente su amor por el árbol anclado en el césped variopinto como columna monumental de un paisaje articulado cual perfecta arquitectura. Para esta suerte de interpretación emplea breve gama cromática a base de una sencilla trilogía de amarillo, azul y verde combinada armoniosamente para establecer tres manchas de color.

El paisaje andaluz constituye la tercera y definitiva fuente de inspiración para el pintor Félix Lacárcel, siendo uno de los capítulos más interesantes dentro del género por lo que se refiere al número de obras y variedad de las mismas.

Andalucía representa para el artista su tierra adoptiva a la que quedará finalmente vinculado y a la que dedica el resto de su producción pictórica e incluso su posterior quehacer en el campo de la restauración artística.

Se instala en Sevilla en 1914 al ser nombrado Profesor de Ascenso de la Escuela Industrial y de Artes y Oficios con destino a las enseñanzas de Dibujo Artístico. Es el momento en que la ciudad vive el esplendor de su ambiente regionalista. Gustavo Bacarisas acaba de instalarse también en ella encabezando la que algunos han dado en llamar la "Generación artística de 1914"7 que va a representar la idiosincrasia andaluza con no pocas dosis de renovación formal frente a los tradicionalistas del luminismo como G. Bilbao. El Ateneo y Sociedad de Excursiones, bajo la inspiración de José María Izquierdo, Blas Infante y otros ideólogos, al que se sentirá vinculado todo el grupo generacional -incluido Lacárcel- es el portavoz a través de su revista "Bética" de todo el

7. SÁNCHEZ PEDROTE, E.: "Santiago Martínez y el entorno sevillano de su tiempo". C'atálogo homenaje al pintor. Sevilla, 1980. S/p. 
movimiento artístico y cultural que propende al conocimiento de todo lo autóctono, siendo el paisaje, junto a algunos resabios costumbristas, el género preferido por los pintores del Regionalismo.

En este ambiente de revisionismo artístico y cultural en el que Lacárcel, como ya se dijo, se mantiene dentro de un particular eclecticismo, no es extraño que el joven pintor de 31 años busque la inspiración en la variopinta e insólita todavía geografía de casi todas las provincias meridionales, algunas de las cuales ya había conocido con anterioridad en su búsqueda juvenil por todo lo largo y ancho del mapa peninsular. En este sendio, antes de la fecha señalada, había ejecutado, que se sepa, varias versiones de El Chorro de Málaga ${ }^{8}$ en las que se siente sobrecogido por la desnuda y brava naturaleza del lugar. Se trata de paisajes grandiosos, recios y viriles en los que consigue captar el espectacular maridaje rocosidad-agua inundado de diáfana luz cuyos reflejos en el aire son más fugaces que el mismo agua.

También en 1913 fecha sendos paisajes urbanos y monumentales de Granada y Sevilla. En el primero representa el Patio de la acequia del Generalife $e^{9}$ con su primitiva fisonomía antes de las restauraciones de tan importante conjunto nazarí efectuadas en 1922 y 1926 . De nuevo aborda el pintor un tema de jardín aunque en esta ocasión a la manera andaluza, islámica, es decir como patio cerrado ("hortus conclussus", diríase) en donde cabe la trilogía: arquitectura (pabellón meridional), agua (que corre por la acequia en el centro del patio y manando del surtidor) y vegetación o floresta muy poblada de toda clase de plantas (arrayanes, naranjos, cipreses, rosales...) todo ello tratado con un carácter barroquizante, cual es el espíritu de lo andaluz en general y de la Alhambra en particular.

Con respecto al aludido paisaje de Sevilla fechado en el décimotercer año del siglo, representa el Patio de los naranjos de la catedral ${ }^{10}$, abordando de nuevo en él la trilogía mencionada en el anterior: la arquitectura (la Puerta del Perdón), el agua (la que mana del surtidor de la fuente central) y la vegetación (los cinco naranjos que dan nombre al patio) representados como sendos puntos de referencia de la composición.

Posteriormente el pintor, cada vez más identificado con las tierras andaluzas, plasmará sucesivamente no tanto los renombrados monumentos artísticos sino aquellos otros aspectos más populares y menos conocidos pero cargados de atractivo por su pintoresquismo. De 1917 es una interesante representación del Corral del Conde de Sevilla (18 x 23. O/cartón. Prop. part.) que manifiesta la gracia y espontaneidad habituales entonces por su autor quien se deja seducir

8. Se conocen algunos ejemplares en otras tantas colecciones particulares, en óleos sobre lienzo y de formato $40 \times 26 \mathrm{cms}$

9. $70 \times 54.0 / 1$. Prop. part.

10. 100x 80. O/1. Prop. part. 
por tan encantador enclave haciendo presente al propio tiempo su destreza ya demostrada en la interpretación del maridaje arquitectura-vegetación, constituyendo la primera el fondo de la composición mientras ésta, muy exhuberante, ocupa la mayor parte del cuadro.

Su interés por lo volumétrico se aprecia dos años después en el paisaje urbano hispalense: El mercadillo del "Jueves" (60 x 34. O/l. 1919. Prop. part.). Ahora trata con habilidad la luz que, diáfana y difusa, envuelve las casas de la popular calle de la Feria del barrio de La Macarena captada desde un punto de vista alto y enfilada en perspectiva axial por lo que domina en profundidad buena parte de tan larga vía y permite, al mismo tiempo, contemplar en primer plano a un nutrido grupo de personas que acuden al popular mercadillo, del que destacan los blancos tenderetes, la cacharrería esparcida por el suelo, las jaulas colgadas de las paredes y un sin fin de objetos que constituyen como un gran bodegón lleno de vida. Además, incorpora el pintor, haciendo gala de un cierto ingenuismo, algunas casas del entorno -la mayoría aún hoy en pie- unas con balcones adornados con macetas de flores multicolores o con caídas de esparto, otras con toldos en sus pisos bajos. También con evidente afán descriptivo, aparecen en sucesivos planos de profundidad que establecen una estudiada perspectiva: la vieja torre de Omnium Sanctorum; la bocacalle de Peris Mencheta; una pintoresca caballería con serones montada por un hombre, y un típico tranvía de la época.

Aprovechando las estancias veraniegas fuera de la capital hispalense, Lacárcel pinta a partir de 1919 en la costa gaditana y en las serranías de Sevilla y Huelva.

En el bello litoral Atlántico meridional se detiene en representar en 1920 algunos cuadros que constituyen la reafirmación de aquel magistral luminismo aprendido en su primera juventud. Rota es el lugar elegido. Aquí realiza, ora espléndidas panorámicas de paisajes con figuras captadas en la playa, ora algunas vistas del pueblo en la que predomina el blanco caserío que, en atractiva bicromía, alterna con el límpio azul del cielo que llega a confundirse con el mar. En algunas de estas últimas aparecen deliciosos rincones de recoletos e íntimos patios encalados, en los que sencillas macetas situadas bajo las alquerías y entre naranjos y limoneros ponen la nota de color en ambiente cargado de paz e intimidad.

El paisaje de la localidad serrana de Guillena ${ }^{11}$ constituye una espléndida panorámica abierta en derredor dejando ver la mansa rivera atravesando la comarca por entre arbustos, chopos y sinuosas lomas medio descarnadas. Lo agreste del terreno y la objetividad de la representación destaca frente a cualquier otra consideración de carácter humano.

11. Existen varias versiones de 1919 , de $120 \times 74$ y $118 \times 123 \mathrm{~cm}$. respectivamente, en una misma colección privada. 
Varios ejemplares de El Pedroso siguen la línea del anterior en su deseo de captar la geología de la zona norte de Sevilla ${ }^{12}$. Por lo común en todos ellos aparece una luminosa paleta de tonos blanquiverdes tratados a golpe de pincel que acusan cierta intencionalidad puntillista ${ }^{13}$.

La serranía onubense, lugar privilegiado por su atractivo natural, sugestiona igualmente a pintor tan ávido por captar en toda su grandeza los singulares encantos de Aracena y su comarca. Le interesa, como en anteriores ocasines, el binomio naturaleza-arquitectura en sencilla pero al tiempo grandiosa simbiosis de la que destaca el tono blanquiverde, como si de un auténtico poema pictórico a Andalucía se tratase.

Entre los paisajes dedicados a la zona destaca un precioso ejemplar de Aracena (1924. 45 x 30. O/. Prop. part.) en qu aparece el caserío extendido por la campiña junto al que se eleva el majestuoso montículo en cuya cima sobresale la iglesia del Castillo rodeada de jaras, tomillos, romeros y jaguarzos.

Semejantes en composición son los paisajes de la pintoresca localidad de Fuenteheridos: unos muestran su templo parroquial, otros algunas huertas con personajes que avivan aún más la representación.

La actividad de Lacárcel como pintor comienza a declinar con la Guerra Civil. Tras ella se dedica especialmente a la restauración artística, labor verdaderamente encomiástica y muy necesaria entonces debido a los estragos que la contienda ocasionó en el patrimonio monumental tanto público como privado. Desde entonces, si bien no abandona definitivamente los pinceles, sus obras acusan el agotamiento estético propio de un artista hasta entonces muy activo, ya entrado en años y desencajado artísticamente; por ende, sus creaciones de última época reiteran una estética ya caduca para los nuevos tiempos y cuya temática seguirá siendo el paisaje que ahora iene como inspiración las bellezas de su residencia de descanso en la localidad aljarafeña de Villanueva del Ariscal, "Villa Valencia". Aquí el viejo maestro levantino, aunque algo cansado ya, sigue laborando, ahora pausada pero, como siempre, amorosamente, fechando sus últimos paisajes a partir de la década de los cincuenta, eco nostálgico pero todavía sonoro de aquellos realizados en plena fecundidad juvenil cuando el género gozaba aún de actualidad y reconocimiento como uno de los más practicados y sugerentes dentro de la Pintura novecentista.

12. En 1929 hizo el artista varios apuntes y obras en diferentes tamañoł pertenecientes a colecciones particulares.

13. Puede entenderse esta técnica de Lacárcel como lainterpretación personal del estilo constructivista de Bacarisas impuesto a determinados pintores de su entorno (Juan M. Sánchez, José María Labrador, José Martínez del Cid), a los que en varias ocasiones hemos llamado "renovadores" y a los que hay quien gusta englobar en la llamada "Generación de la Exposición Iberoamericana de Sevilla", naciđos casi todos a finales de siglo. 


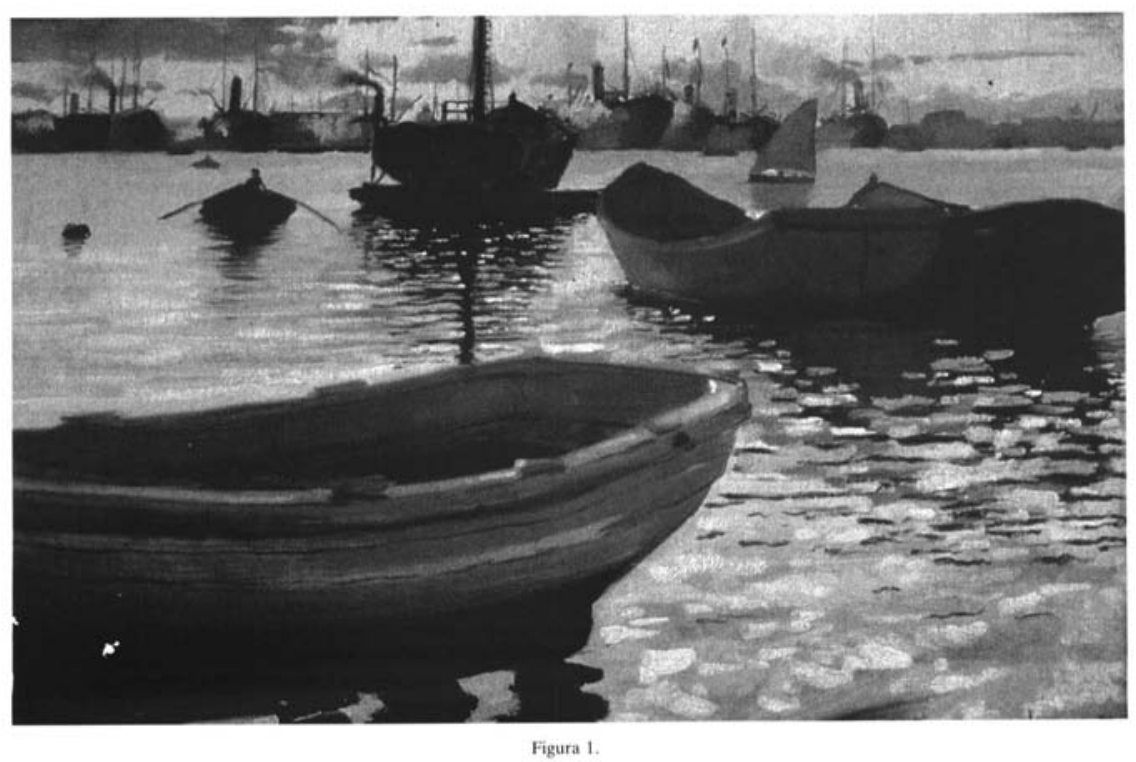




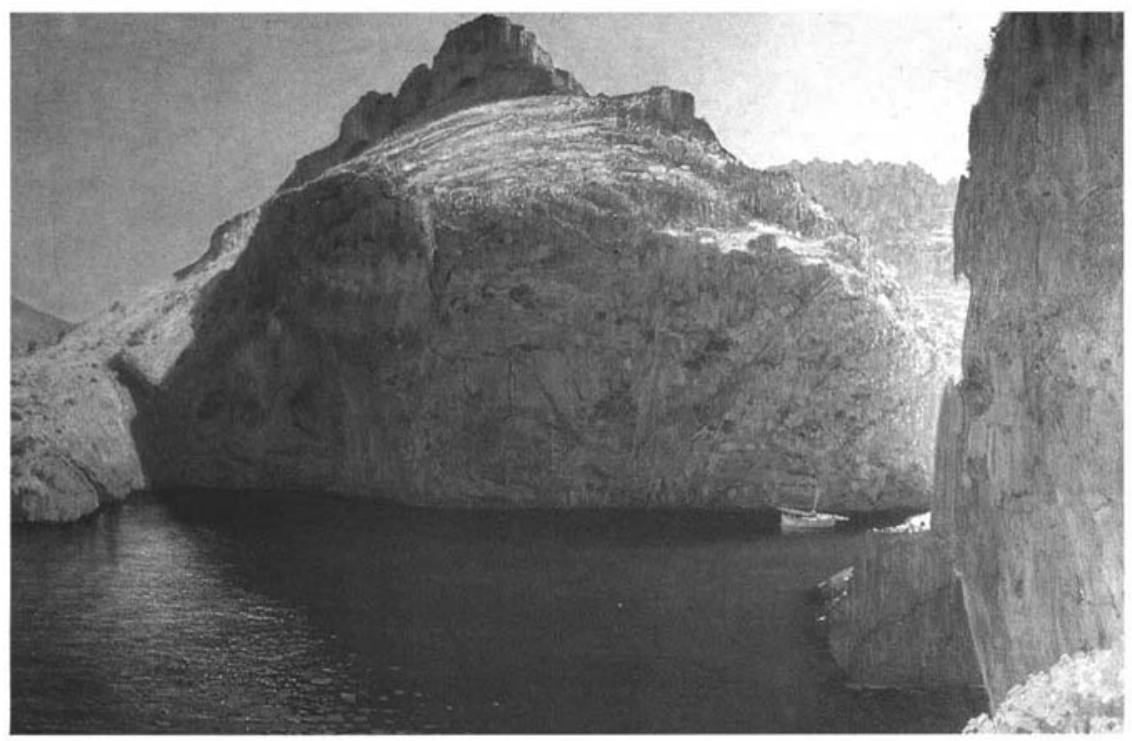

Figura 2. 


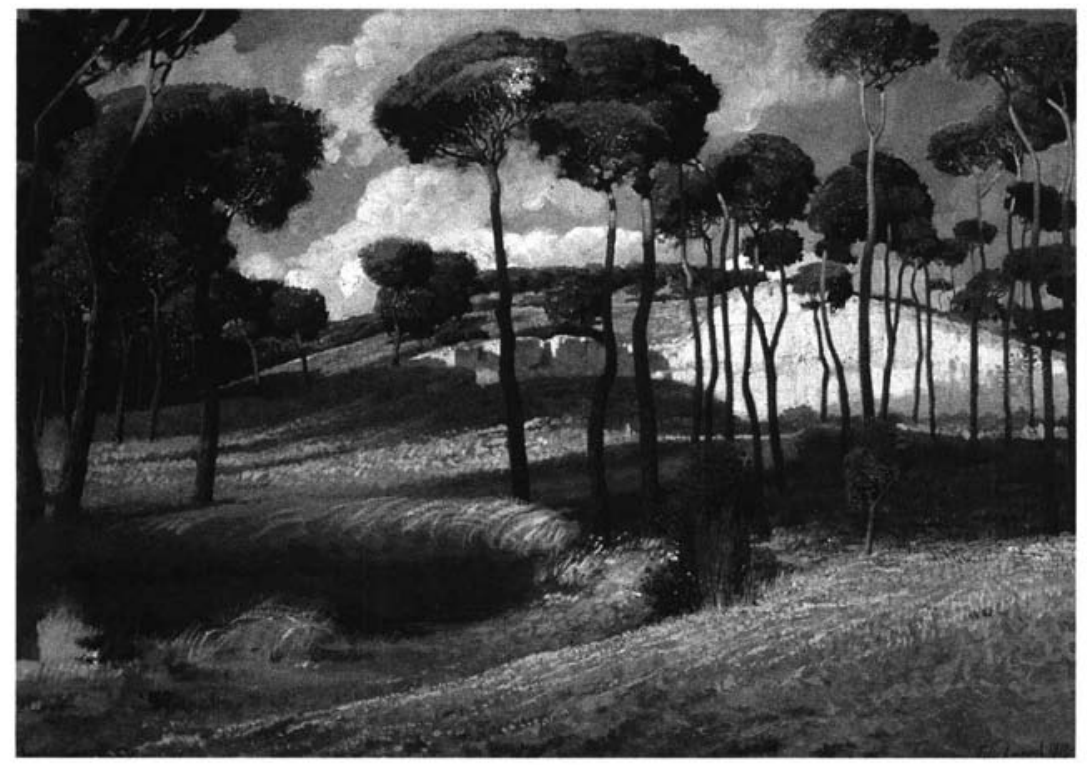

Figura 3.

Pinares de Chamartin. Madrid. 


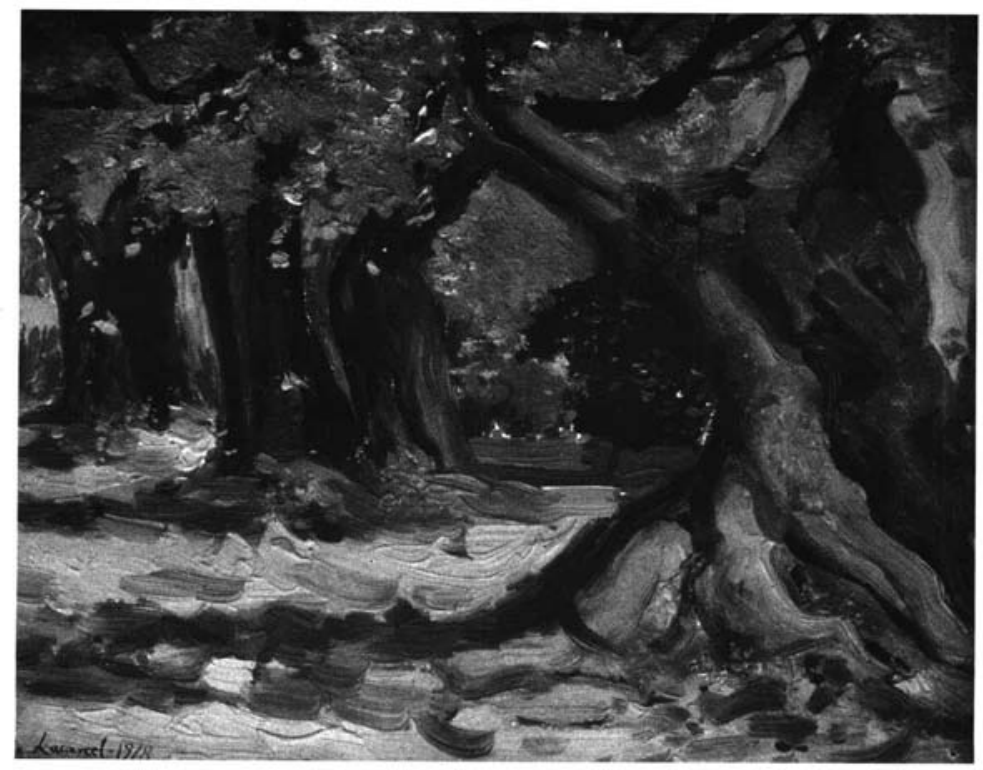

Figura 4.

Arboleda. 1918. 


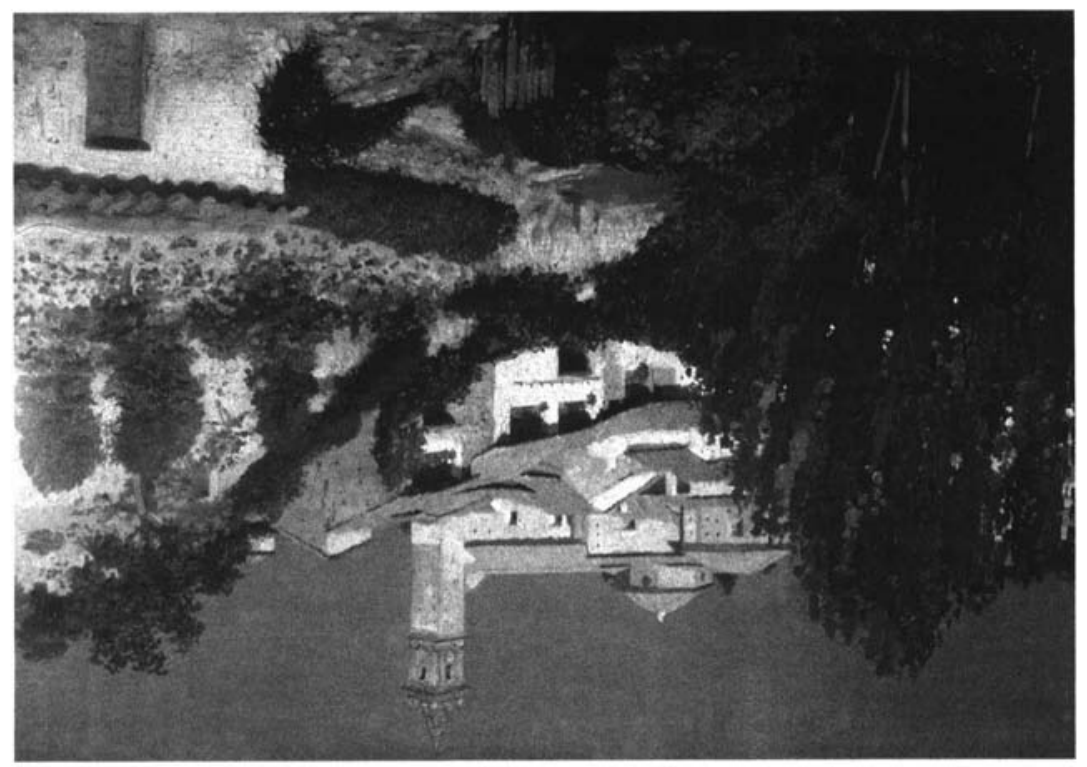




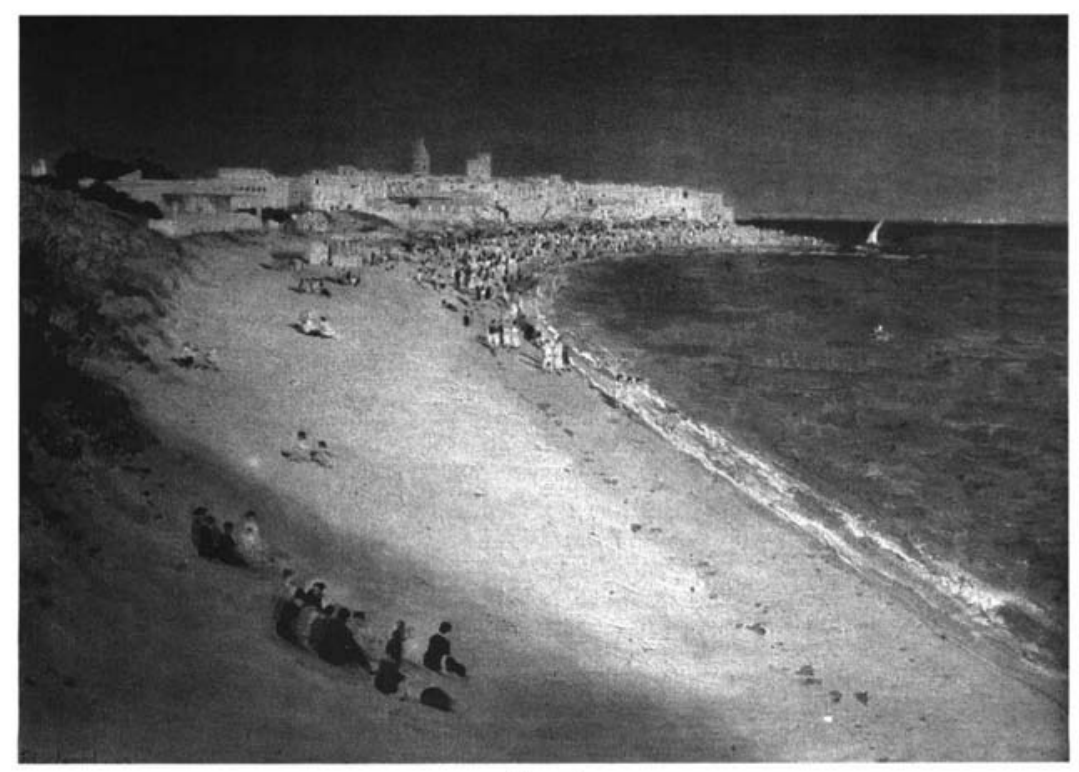

Playa de Rota. Cadiz. 